\title{
Word superiority in word detection
}

\author{
JOSHUA D. STALLER \\ State University of New York, Oswego, New York 13126
}

\begin{abstract}
Observers searched for a single precued word or its nonword anagram under conditions of rapid serial visual presentation (RSVP). A word advantage was found over a wide range of presentation rates (32.160 msec/frame), under yes-no as well as forced choice conditions, and with both one or two input "channels." These results suggest that word superiority in word detection occurs at a perceptual locus.
\end{abstract}

Can prior visual experience facilitate current visual perception?

A good deal of research on this question has focused on letter and word processing. Historically, Cattell (1886) was the first to demonstrate that, under conditions of tachistoscopic exposure, letters that formed a word could be reported more accurately than the same letters in an unfamiliar sequence. In hindsight, it is clear that the word advantage discovered by Cattell might have been due to the perceptual and/or cognitive resources of his observers. Much of the contemporary research on this phenomenon has tried to separate the impact of these resources on stimulus encoding, and two main theoretical viewpoints have emerged (Krueger, 1975). One viewpoint assumes that the word advantage is at a perceptual locus; that is, visual information from a familiar stimulus can be extracted more rapidly and/or is more resistant to interference. A second point of view asserts that the word advantage is due to cognitive interpretation; given incomplete perceptual information, as in tachistoscopic exposure, an observer can more easily infer the components of a stimulus that conforms to familiar patterns and constraints.

Several recent forced-choice studies of the wellknown word superiority effect, in which single letters are processed more quickly or accurately in words than in nonwords, seemed to indicate that visual experience can facilitate perception (Carr, Lehmkuhle, Kottas, Astor-Stetson, \& Arnold, 1976; Purcell, Stanovich, \& Spector, 1978; Reicher, 1969). Each of these studies, however, has faced serious challenges. Massaro (1973) and Thompson and Massaro (1973) argued that cognitive interpretation was not ruled out in Reicher's postcue letter-recognition procedure. Specifically, Thompson and Massaro found that the

The author gratefully acknowledges the assistance of the Research Foundation of the State of New York in providing funding for this project. I am also thankful for the assistance of Mark Eckstein, Joann Rogers, and John DeGroff, who helped collect the data. Portions of this research were presented at the 1981 meetings of the Eastern Psychological Association. Address reprint requests to J. D. Staller, Department of Psychology, SUNY at Oswego, Oswego, New York 13126. visual similarity between the postcued choice alternatives did not influence performance, as if observers had already decided on a response before the alternatives were presented. Furthermore, when observers were informed of the target alternatives and their spatial position in advance, no word superiority effect was obtained. Subsequently, however, Carr et al. were able to demonstrate a word superiority effect with target precuing by introducing uncertainty about the target's position in the stimulus array. But Staller and Lappin (1979) argued that the graphic similarity between target and context letters was not adequately controlled in Carr et al. When graphic similarity was equated across words and nonwords, Staller and Lappin did not find a word superiority effect. (Graphic factors also seem to account for the Purcell et al. findings, as shown recently by Paap and Newsome, 1980.)

Taken together, the available evidence provides little support for the assertion that experience can facilitate the perception of letters within words (see, also, Krueger \& Shapiro, 1979; Massaro, 1979). A different conclusion seems to emerge, however, when observers attend to words as wholes. Specifically, several studies of letter detection have shown that a word superiority effect is more likely to be obtained when observers are encouraged to attend to a word as a whole rather than to a letter within a word (Johnston, 1981; Johnston \& McClelland, 1974). More direct evidence on the detectability of whole words has recently been gathered by Staller and Lappin (1981). The basic paradigm involved rapid, serial visual presentation (RSVP) of 18 six-letter frames. In a yes-no detection task, observers searched consistently for either a word (i.e., CAT) or its nonword anagram (i.e., TCA). In all cases, observers knew the target item in advance, and the individual target and background letters were identical in all conditions; only the letter sequences were varied to compose word and nonword items. The result was that, even after extensive practice, observers detected the word more accurately than the nonword. Furthermore, the lexical characteristics of the background items (e.g., word vs. nonword) had no in- 
fluence on performance. In a second experiment, words (e.g., FIB), orthographic nonwords (e.g., BIF), and familiar acronyms (e.g., FBI) were all detected more accurately than nonorthographic nonwords (e.g., IBF). Thus, familiarity with orthographic rules as well as specific letter sequences enhanced "word" detection in these studies.

The Staller and Lappin experiments on word detection strongly suggest that observers' resources may operate at a perceptual locus. Nevertheless, it might be argued that cognitive interpretation was still possible in the above experiments, particularly since the presentation rates were relatively slow (120 and $160 \mathrm{msec} /$ frame, respectively). Indeed, Krueger and Shapiro (1979) recently studied letter detection using RSVP, and found an interaction between presentation rate and target familiarity. That is, observers detected letter targets more accurately in words than in nonwords, but this difference was reliable only at presentation rates slower than $100 \mathrm{msec} /$ frame. On the basis of these and other findings, Krueger and Shapiro concluded that "Feature extraction seems to be largely accomplished within the first $100 \mathrm{msec}$ following stimulus onset. The fact that word context had little or no effect when the exposure duration was $100 \mathrm{msec}$ or less ... suggests that it aided not feature extraction but the subsequent interpretation process" (1979, p. 665). Since Staller and Lappin used presentation rates slower than $100 \mathrm{msec} / \mathrm{frame}$, it could be argued that cognitive interpretation accounts for their findings as well. In order to address this issue, observers in Experiment 1 searched for words and nonwords over a wide range of presentation rates (40-160 msec/frame).

A second concern was the potential influence of response bias in yes-no detection. Staller and Lappin dealt with this issue by converting raw accuracy data to the unbiased choice theory measure of sensitivity, $\log$ eta $(-\ln \eta)$. However, this transformation is nonlinear and may tend to accentuate word-nonword differences, particularly at higher performance levels. In the present studies, such nonlinearities could pose a problem for the interpretation of any interaction between target familiarity and presentation rate. Thus, in Experiment 2, a forced choice detection procedure was instituted to obviate these problems.

A third experiment was conducted for the following reason. Staller and Lappin (as well as Experiments 1 and 2) employed a divided attention procedure in which observers simultaneously monitored two separate input "channels." In most studies of the word superiority effect, however, information has been presented in a single input channel. In order to provide a more direct comparison with previous research, only one channel was used in Experiment 3.

The results of all three experiments offer converging evidence that word superiority in word detection can occur at a perceptual locus.

\section{EXPERIMENT 1}

Levels of target familiarity (word vs. nonword) and presentation rate $(40,80$, or $160 \mathrm{msec} /$ frame $)$ were combined factorially in a yes-no detection task. Accuracy varied as a function of both variables, but there was no interaction between them.

\section{Method}

Subjects. Six observers (three males, including the author; three females) from the SUNY at Oswego community were tested. With the exception of the author, all were paid for their participation.

Stimulus displays. On each trial, 12 frames containing six uppercase letters were presented in rapid sequence on a computercontrolled television display (Apple 2; RCA 19 in. XL-100). ${ }^{1}$ The six letters in a frame were positioned in a rectangular array, with three letters above and three letters below a central fixation point. The letters in a frame were refreshed every $16 \mathrm{msec}$ and were composed by illuminating the appropriate dots in a $7 \times 7$ matrix. The luminance of the stimuli was set at a low level to minimize visible persistence of the display phosphor. The boundaries of each frame subtended about $1.5 \mathrm{deg}$ horizontally $\times 2.3 \mathrm{deg}$ vertically, and individual letters subtended about $26 \mathrm{~min}$ horizontally $\times 45 \mathrm{~min}$ vertically. Successive frames in a trial were spatially superimposed, and the frame durations were systematically varied across trial blocks (i.e., approximately 40,80, and $160 \mathrm{msec} /$ frame). There was no appreciable delay interval between frames.

A complete list of the three-letter words and nonwords used in this study is provided in the Appendix. Distractor items on each trial were sampled randomly (with replacement) from a set of 12 three-letter patterns. Each distractor shared one letter with the word or nonword target, in an isomorphic spatial position. Other letter positions were filled randomly from the alphabet with the constraint that no letter be repeated within the same three-letter pattern. Thus, for the targets FOX and XFO, the distractor set always contained two items with $F$ in the first position, $O$ in the second, and $X$ in the third, as well as two items with $X$ in the first position, $F$ in the second, and $O$ in the third. Within these constraints, a new set of distractors was constructed after each block of 50 trials. A six-letter frame was composed by selecting two distractor items, one for the upper position in the array and another for the lower position. Prior to each trial, 12 frames were generated randomly with the constraint that the same three-letter distractor item not appear in the same spatial position in two successive frames.

Procedure. Each observer participated in six daily sessions. Each session began with 10 practice trials in the condition corresponding to the first test trials for that day. Practice was followed by six blocks of test trials, with 50 trials per block. Within each block of 50 trials, observers searched consistently for one and only one three-letter target, either a word or its nonword anagram (e.g., FOX or XFO). Target condition (word vs. nonword) was alternated across each trial block, while presentation rate was held constant across two trial blocks and then changed. The order of targets and presentation rates was counterbalanced as much as possible across days and observers.

The sequence of events on each trial was as follows. A fixation point (a "plus" sign) appeared in the center of the television screen. Observers initiated a trial by pressing the space bar on the computer keyboard. The fixation point disappeared, $250 \mathrm{msec}$ elapsed, and then 12 six-letter frames were presented, spatially superimposed. The subject responded by pressing the " $Z$ "' key if a target was detected ("yes") and the "?"' key if it was not ("no"). Feedback was provided by a computer-generated tone, which sounded if the response was correct. Within a block of 50 trials, the target-present and target-absent trials were equiprobable and randomly intermixed. The target's position within the frame 
sequence was determined randomly with the constraint that it never appear in the first or last two frames. Observers viewed the displays binocularly in a dimly lit room from a distance of about 33 in., using a chinrest.

\section{Results and Discussion}

The mean accuracy data are shown in Figure 1. In general, words were detected (mean $=66 \%$ ) more accurately than nonwords (mean $=59 \%$ ). An analysis of variance indicated that the main effect of target familiarity was significant $[F(1,5)=320, p<.001]$. Detection accuracy also improved with slower presentation rates $[F(2,10)=164, p<.001]$. There was, however, no interaction between familiarity and presentation rate $(p=.27)$, and no other effects of the analysis of variance reached significance (all ps $>.37$ ). A Newman-Keuls test indicated that words were detected significantly more accurately than nonwords at presentation rates of 40 and $160 \mathrm{msec}(p<.05)$, but not at $80 \mathrm{msec}$.

For a second analysis, the data were partitioned into hits and false alarms. There were more hits on words than on nonwords (mean $=66 \%$ vs. $58 \%$, respectively), as well as fewer false alarms (mean = $34 \%$ vs. $40 \%$ ). By analysis of variance, this interaction was significant $[F(1,5)=475, p<.001]$. Newman-Keuls comparisons indicated significant differences between words and nonwords on both hits and false alarms $(p<.05) .^{2}$

The results of Experiment 1 suggest that prior visual experience can facilitate perception during word detection; a word superiority effect was obtained at presentation rates well below $100 \mathrm{msec}$, and there was no interaction between familiarity and presenta-

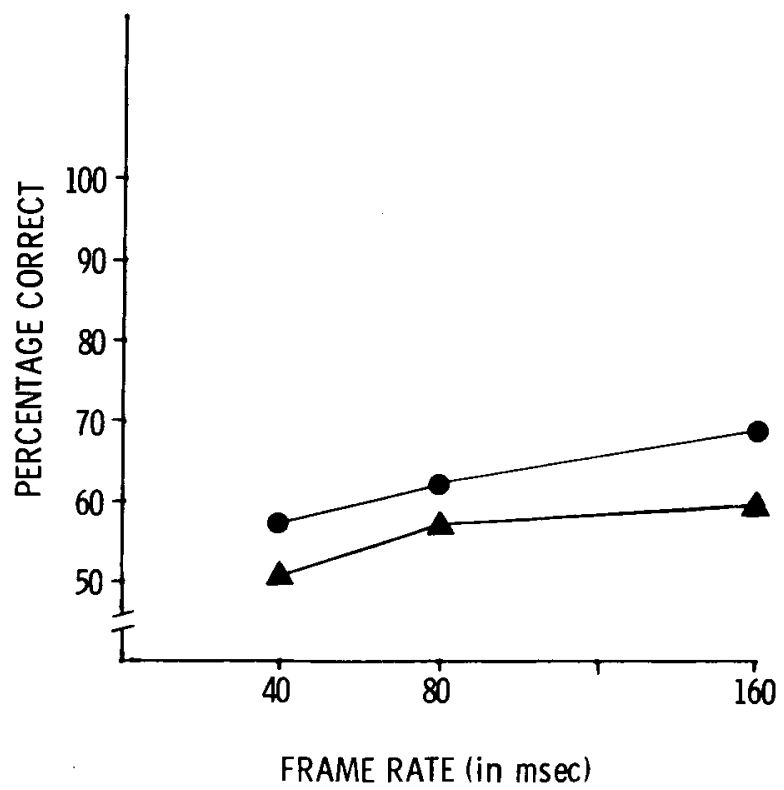

Figure 1. Mean percentage correct for words (circles) and nonwords (triangles) in Experiment 1. tion rate. The reader will recall that in Krueger and Shapiro's study of letter detection, familiarity and presentation rate did interact, with no reliable word advantage below $100 \mathrm{msec}$. Although there were a number of procedural differences between Krueger and Shapiro (1979) and the present study, the crucial difference seems to be the nature of the discrimination that was required of the observer. That is, observers apparently use different resources in letter and word detection. In letter detection, at rapid presentation rates, observers attend to graphic features in order to discriminate between target and nontarget letters (e.g., Johnston, 1981; Staller \& Lappin, 1979). Furthermore, it has been shown that graphic features and orthographic knowledge make independent contributions to letter-detection accuracy (Massaro, 1979). In word detection, however, observers are able to use both orthographic and stimulus-specific knowledge to facilitate the detection of familiar letter sequences (e.g., both this experiment and Staller \& Lappin, 1981). Thus, letter detection tends to direct the observer's attention to the graphic features of an array, whereas word detection encourages the use of supraletter features, such as orthography (see also Johnston \& McClelland, 1974).

Finally, since there were more hits and fewer false alarms on words than on nonwords, it is unlikely that the word superiority effect in Experiment 1 can be explained by response bias. Converging evidence on this point is provided below.

\section{EXPERIMENT 2}

Can a word advantage be obtained under forced choice conditions? This question was answered in the affirmative in Experiment 2, in which observers searched for words and nonwords in a two-interval forced-choice task. Again, accuracy varied as a function of familiarity and presentation rate, but these variables did not interact.

\section{Method}

Subjects. Ten observers (three males, seven females) were tested. Six had had prior experience with the RSVP paradigm, but not with the forced-choice procedure or with the specific target and background items chosen for Experiment 2. All were paid for their participation.

Stimulus displays. In contrast with Experiment 1, the 12 frames in a trial were subdivided into two 6-frame sequences, with a .5 -sec pause between them. Presentation rates were either 32 or $64 \mathrm{msec} /$ frame.

Procedure. Observers were divided into two groups based on presentation rate. One group viewed all stimuli at $32 \mathrm{msec} / \mathrm{frame}$, while the second group viewed all stimuli at $64 \mathrm{msec} / \mathrm{frame}$. There were three daily sessions: one practice session, followed by two test sessions. For a given observer, targets were kept constant within a session, but varied across sessions. On each trial, the target was placed randomly in either the first or second set of six frames, with the constraint that it never appear in the first or last two frames in a six-frame sequence. Target-first and target-second trials were equiprobable and randomly intermixed. Responses 
Table 1

Mean Percentage Correct in Experiments 2 and 3

\begin{tabular}{ccc}
\hline \multirow{2}{*}{$\begin{array}{c}\text { Exposure Duration } \\
\text { (in Milliseconds) }\end{array}$} & Word & Nonword \\
\cline { 2 - 3 } & Experiment 2 \\
32 & 55.0 & 52.4 \\
64 & 64.3 & 59.4 \\
& Experiment 3 & \\
48 & 64.8 & 60.6 \\
64 & 75.4 & 68.5 \\
\hline
\end{tabular}

were signaled by pressing the " $\mathrm{X}$ " key if the target was detected in the first set of frames, or the " $>$ " key if it was detected in the second set.

In all other respects, the stimuli and procedure were the same as in Experiment 1.

\section{Results and Discussion}

As shown in Table 1, words were detected more accurately than nonwords, a difference that was significant by analysis of variance $[F(1,8)=30, p<.001]$. Performance also improved with slower presentation rates $[F(1,8)=13, p<.01]$. There was no interaction between familiarity and presentation rate $(p=.12)$, nor were any other effects significant (all ps $>.31$ ). A Newman-Keuls analysis indicated that the word advantage was significant at both 32 and $64 \mathrm{msec}$ $(p<.05)$. Thus, word superiority in word detection can be obtained under forced-choice conditions, a finding which effectively rules out response bias as an explanation of the effect.

\section{EXPERIMENT 3}

In Experiments 1 and 2 (as well as in Staller \& Lappin, 1981), observers divided their attention between two three-letter "channels" presented above and below a central fixation area. However, most studies of the word superiority effect have not required divided attention. In order to provide a more direct comparison with other studies, observers in Experiment 3 searched for three-letter targets presented in a single three-letter channel. Once again, a word superiority effect was obtained.

\section{Method}

Subjects. Fourteen new, naive observers (eight males, six females) were recruited from psychology classes at SUNY Oswego. All received class credit for their participation.

Stimulus displays. In contrast with Experiment 2, each frame contained only three letters. Two "plus" signs, horizontally spaced about $3.7 \mathrm{deg}$ apart, served to demarcate a central fixation area. Presentation rates were either 48 or $64 \mathrm{msec} / \mathrm{frame}$. All other aspects of the stimuli and procedures were the same as in Experiment 2.

\section{Results and Discussion}

Average scores are provided in Table 1. As in previous experiments, there was a word superiority effect $[F(1,12)=27, p<.001]$, as well as an effect of presentation rate $[F(1,12)=11, p<.01]$. Again, these factors did not interact $(p=.23)$ and no other effects reached significance (all ps $>.06$ ). A NewmanKeuls comparison indicated that words were detected more accurately than nonwords at both presentation rates $(p<.05)$. Clearly, the word superiority effect in word detection is not limited to conditions of divided attention.

\section{GENERAL DISCUSSION}

These experiments addressed the basic question of whether prior visual experience can facilitate current visual perception. In an RSVP task, observers searched for a single target (either a word or its nonword anagram) over a wide range of presentation rates (32-160 $\mathrm{msec} /$ frame), under yes-no as well as forced choice conditions and with either one or two input channels. The striking aspect of these data is the robustness of the word superiority effect, which prevailed across all the above conditions and variations. Since the target was precisely specified in advance, and since physical and statistical aspects of the stimuli were equated across conditions, these results strongly suggest that visual experience can indeed facilitate visual perception.

What might be the perceptual locus of the word superiority effect in word detection? Following the logic of Krueger and Shapiro (1979), the present study implicates a familiarity effect at the locus of feature extraction. By precuing a single target, the task demands on memory storage and comparison were minimized. In addition, by presenting stimuli at very rapid rates, the opportunities for cognitive interpretation were considerably reduced. Thus, by the process of elimination, it seems possible that visual features might have been extracted more efficiently from words than from nonwords in the present experiments. Clearly, however, additional converging operations are required to strongly justify such a conclusion. In particular, it would be useful to systematically manipulate the visual features in the word and nonword target stimuli. According to Krueger and Shapiro, observers should be able to detect the deletion of features more accurately in words than in nonwords if the locus of the word superiority effect is at feature extraction.

In contrast with Krueger and Shapiro, Johnston and McClelland (1980; see also Johnston, 1981) have outlined a hierarchical model of word identification that includes separate and distinct perceptual codes for features, letters, and words. In this model, the word advantage arises not at feature extraction, but, instead, at two stages "upstream," at which point the visual codes for words are activated. Specifically, the visual codes for words are thought to be more resistant to inhibition from pattern masking than are 
the visual codes for letters. The power of this model is illustrated by the prediction that the lexical characteristics of a pattern mask (e.g., word vs. nonword) will not influence word vs. nonword target detection, a prediction that has received empirical support (Johnston \& McClelland, 1980; Staller \& Lappin, 1981). On the other hand, the strict version of the model implies that the deletion of valid visual features from a letter, or the insertion of invalid ones, should have a profoundly negative impact on performance. Thus, the predictions of Johnston and McClelland and of Krueger and Shapiro could be tested further by manipulating the visual features in the target arrays.

The present results are also compatible with the idea that a familiar percept is more likely to elicit an "automatic attentional response"' (e.g., Schneider \& Shiffrin, 1977). In support of automaticity theory, Staller and Lappin (1981) have shown that performance on nonwords becomes more "wordlike" with practice. Furthermore, a number of subjective reports indicate that familiar targets seem to "pop out" from the distractor background (Adams, 1979; Schneider \& Shiffrin, 1977; Staller \& Lappin, 1981). It is not yet clear, however, whether the automatic attentional response is a cause or consequence of perceptual clarity in RSVP. The results of Experiment 3 seem to support the latter alternative; word superiority in word detection was found under conditions of undivided attention.

In conclusion, the present study adds to the growing body of evidence (e.g., Adams, 1979; Johnston, 1981; Solman, May, \& Schwartz, 1981; Staller \& Lappin, 1981) that, at least in word processing, visual experience can facilitate visual perception. The determination of the specific perceptual locus of this effect, however, awaits further research.

\section{REFERENCES}

Adams, M. J. Models of word recognition. Cognitive Psychology, 1979, 11, 133-176.

Carr, T. H., Lehmkuhle, S. W., Kottas, B., Astor-Stetson, E. C., \& ARnold, D. Target position and practice in the identification of letters in varying contexts: A word superiority effect. Perception \& Psychophysics, 1976, 19, 412-416.

Cattell, J. M. The time taken up by mental operations. Mind, $1886,11,220-242$.

Johnston, J. C. Effects of advance precuing of alternatives on the perception of letters alone and in words. Journal of Experimental Psychology: Human Perception and Performance, 1981, 7, 560-572.

Johnston, J. C., \& McClelland, J. L. Perception of letters in words: Seek not and ye shall find. Science, 1974, 184, 1192-1194.

Johnston, J. C., \& MCClelland, J. L. Experimental tests of a hierarchical model of word identification. Journal of Verbal Learning and Verbal Behavior, 1980, 19, 503-524.

KRUEGER, L. E. Familiarity effects in visual information processing. Psychological Bulletin, 1975, 82, 949-974.
Krueger, L. E., \& Shapiro, R. G. Letter detection with rapid serial visual presentation: Evidence against word superiority at feature extraction. Journal of Experimental Psychology: Human Perception and Performance, 1979, 5, 657-673.

Massaro, D. W. Perception of letters, words and nonwords. Journal of Experimental Psychology, 1973, 100, 349-353.

MASSARo, D. W. Letter information and orthographic context in word perception. Journal of Experimental Psychology: Human Perception and Performance, 1979, 5, 595-609.

PAAP, K. R., \& Newsome, S. L. Do small visual angles produce a word superiority effect or differential lateral masking? Memory \& Cognition, 1980, 8, 1-14.

Purcell, D. G., Stanovich, K. E., \& Spector, A. Visual angle and the word superiority effect. Memory \& Cognition, 1978, 6, 3-8.

Reed, A. V. Microcomputer display timing: Problems and solutions. Behavior Research Methods \& Instrumentation, 1979, 11, 572-576.

REICHER, G. M. Perceptual recognition as a function of meaningfulness of stimulus material. Journal of Experimental Psychology, 1969, 81, 275-280.

Schneider, W., \& Shiffrin, R. M. Controlled and automatic human information processing: I. Detection, search and attention. Psychological Review, 1977, 84, 1-66.

Solman, R. T., MAY, J. G., \& Schwartz, B. D. The word superiority effect: A study using parts of letters. Journal of Experimental Psychology: Human Perception and Performance, 1981, 7, 552-559.

Staller, J. D., \& Lappin, J. S. Word and nonword superiority effects in a letter detection task. Perception \& Psychophysics, $1979,25,47-54$.

Stallek, J. D., \& Lappin, J. S. The visual detection of multiletter patterns. Journal of Experimental Psychology: Human Perception and Performance, 1981, 7, 1258-1272.

Thompson, M. C., \& Massaro, D. W. Visual information and redundancy in reading. Journal of Experimental Psychology, $1973,98,49-54$.

\section{NOTES}

1. Subsequent to Experiment 1, the Apple 2 computer was modified (after Reed, 1979) to allow for more precise control over presentation rates. Clearly, this modification did not alter the general pattern of results.

2. In a partial replication of Experiment 1, five observers (including two who had participated in Experiment 1) were tested at presentation rates of 32,64 , and $128 \mathrm{msec}$, with 4 frames per trial instead of 12 . The overall accuracy levels were slightly higher, but the general outcome was the same. There were significant main effects of familiarity and presentation rate $(p<.01$ and $p<.001$, respectively), but these variables did not interact $(p=.17)$. All other effects were nonsignificant $(p>.15)$. In contrast with Experiment 1 , the Newman-Keuls analysis revealed significant differences between words and nonwords only at $128 \mathrm{msec}$. An additional analysis of variance found more hits and fewer false alarms on words than on nonwords $(p<.01)$. In contrast with Experiment 1 , a Newman-Keuls analysis revealed significant differences only on hits.

These data are in general agreement with Experiment 1, although the word-nonword differences were not quite as robust in replication. The absence of a statistically significant word advantage below $100 \mathrm{msec}$ (by Newman-Keuls test; note, however, that familiarity and presentation rate did not interact) was probably due to two factors: the use of fewer observers and the use of fewer stimulus frames (four frames may not have provided a reliable pattern mask, particularly at rapid presentation rates). 
APPENDIX

Word and Nonword Targets (Experiments 1-3)

$\begin{array}{ll}\text { BET } & \text { TBE } \\ \text { BUS } & \text { BSU } \\ \text { CAP } & \text { PCA } \\ \text { DOG } & \text { GDO } \\ \text { FIB } & \text { IBF } \\ \text { FOR } & \text { OFR } \\ \text { GAP } & \text { APG } \\ \text { JOB } & \text { JBO } \\ \text { RED } & \text { EDR } \\ \text { SIR } & \text { ISR } \\ \text { TOP } & \text { PTO }\end{array}$

$\begin{array}{ll}\text { BID } & \text { DBI } \\ \text { BUT } & \text { TBU } \\ \text { COD } & \text { ODC } \\ \text { FAD } & \text { ADF } \\ \text { FIG } & \text { GFI } \\ \text { FOX } & \text { XFO } \\ \text { GEM } & \text { EGM } \\ \text { LAB } & \text { LBA } \\ \text { RIP } & \text { IPR } \\ \text { SOW } & \text { WSO } \\ \text { VAT } & \text { VTA }\end{array}$

BUG GBU

$\mathrm{CAB} \quad \mathrm{BCA}$

CUB BCU

FAR RFA

FIX XFI

FUR UFR

JET ETJ

PAW APW

SOB BSO

SAT TSA

WAR RWA

(Manuscript received August 3, 1981;

revision accepted for publication November 2, 1981.) 